\title{
Latex agglutination test based prevalence of Toxoplasma gondii in native Korean cattle
}

\author{
Eun-Sik Song ${ }^{1}$, Sang-Il Jung ${ }^{1}$, Bae-Keun Park ${ }^{2}$, Myung-Jo You ${ }^{3}$, Duck-Hwan Kim ${ }^{1}$, Kun-Ho Song ${ }^{1, *}$ \\ ${ }^{1}$ Research Institute of Veterinary Medicine and Laboratory of Veterinary Internal Medicine, and \\ ${ }^{2}$ Laboratory of Veterinary Parasitology, College of Veterinary Medicine, Chungnam National University, \\ Daejeon 305-764, Korea \\ ${ }^{3}$ Laboratory of Veterinary Parasitology, College of Veterinary Medicine and Biosafety Research Center, \\ Chonbuk National University, Jeonju 561-756, Korea
}

(Accepted: March 1, 2011)

\begin{abstract}
The prevalence of Toxoplasma (T.) gondii was surveyed using a latex agglutination test (LAT) in native Korean cattle. A blood sample was collected from female 105 cattle in the Daejeon area of Korea. All cattle were asymptomatic and had not received any prophylactic treatment for $T$. gondii. Blood samples were collected via the caudal vein. The cattle ranged in age from 2 6 years (mean 3.7 years). LAT detected antibody to $T$. gondii in four of $105(3.8 \%)$ cattle. However, the hazard analysis and critical control point protocol has been applied to cattle farms and beef traceability has been strengthen.
\end{abstract}

Keywords : LAT, native Korean cattle, prevalence, Toxoplasma gondii

Toxoplasma (T.) gondii is an obligate intracellular parasite and a tissue cyst-forming coccidian $[2,6]$. If a woman is infected during pregnancy, the microbe may be transmitted vertically by tachyzoites that are passed to the fetus via the placenta. Horizontal transmission can occur via tissue cysts, by ingesting infectious oocysts from the environment or by ingesting tissue cysts or tachyzoites contained in the meat or primary viscera of many different animals [20]. Transmission of $T$. gondii involves the intermediate or fecal exudates of definitive hosts [3]. The parasites can be transmitted in the muscles of edible animals. Tissue cysts of $T$. gondii contained in meat of livestock are also an important source of human infection [10]. T. gondii may be transmitted from definitive to intermediate hosts, from intermediate to definitive hosts, as well as between definitive and intermediate hosts [20].

Although asymptomatic infections are common in cattle, gastrointestinal signs or abortions occasionally occur. Especially, toxoplasmosis is important as a causative agent of a zoonosis because it may cause abortion or congenital disease in woman infected during pregnancy $[1,12]$. T. gondii has been studied most intensively among the coccidia. In 1953, what was thought to be clinical toxoplasmosis in cattle was reported for the first time in the United States. Since then, clinical cases of this disease among cattle have been reported by many authors in various countries. In several US serological studies, positive response rates among cattle in northern California [20] and 38\% in Montana [16]. The prevalence in South Korea is unclear, although the diagnosis of toxoplasmosis in Korea has been successful using the latex agglutination test (LAT) [13-15, 18].

In the current study, LAT were used to examine the prevalence of $T$. gondii infection in native Korean cattle in the Daejeon area. This study blood samples collected from 105 female cattle $(n=1$, per animal) from February to April, 2009, in the Daejeon area on a Korean native cattle farm. All cattle were asymptomatic and had not received any prophylactic treatment for $T$. gondii. Blood samples were collected via the caudal vein. The cattle ranged in age from $2 \sim 6$ years (mean 3.7 years). The serum samples were each collected in a vacuum tube that was free of anticoagulant. Each sample was centrifuged at 4,000 rpm for $10 \mathrm{~min}$ and the serum was

*Corresponding author

Tel: +82-42-821-6789, Fax: +82-42-821-6703

E-mail:songkh@cnu.ac.kr 
Table 1. LAT-based prevalence of Toxoplasma gondii in native Korean cattle

\begin{tabular}{lrc}
\hline \hline Titers & No. of examined & Positive rate $(\%)$ \\
\hline$<1: 16$ & 101 & 96.2 \\
$1: 32^{\mathrm{n}}$ & 4 & 3.8 \\
$1: 64$ & 0 & 0 \\
$1: 128$ & 0 & 0 \\
$1: 256$ & 0 & 0 \\
$1: 512$ & 0 & 0 \\
$1: 1024$ & 0 & 0 \\
\hline Total & 105 & 100 \\
\hline
\end{tabular}

$\mathrm{n}$ : positive criterion

stored at $-70^{\circ} \mathrm{C}$ until examined by LAT.

The microtiter-based Toxotest-MT toxoreagent kit for determination of Toxoplasma antibody titer (Eiken Chemical, Japan) was used to examine Toxoplasma antibody in serum. The kit contains a latex suspension $(0.1 \%$ suspension of polystyrene latex coated with toxoplasma antigen), buffer solution (0.2 M 2-amino-2 methyl-1 propanol-HCl buffer solution), positive control and a microtiter reaction tray with seven U-shaped wells. Each well received $25 \mu \mathrm{L}$ of the buffer solution. Five hundred microliters of test serum was dispensed into a small test tube followed by $350 \mu \mathrm{L}$ of the buffer solution, to dilute the serum $1: 8$. Twenty-five microliters of the diluted serum was dispensed into the first well using a capillary pipette microdiluter. The contents were mixed to make a 1:16 dilution and serial 2-fold dilutions were made in the remaining wells. Each well then received $25 \mu \mathrm{L}$ of the latex suspension using a dropper. The contents of each well were mixed by gentle agitation of the tray, which was then placed on a horizontal surface and covered to avoid evaporation of the reaction mixture. After $12 \mathrm{~h}$, the resulting agglutination pattern was recorded. An antibody titer exceeding $1: 32$ was a positive result (Table 1).

Toxoplasmosis is a zoonosis that is affected by public sanitation. T. gondii prevalence of cattle is not so high in Korea. Elsewhere, a European studies reported parasites in the tissues of calves and cows [7], and raw beef was the source of toxoplasmosis [20] and diarrhea resulting from protozoa infection from sarcocystis. More detailed information is lacking, given the paucity of controlled epidemiological studies concerning the correlation between the prevalence of toxoplasmosis in cattle and in human in physical proximity with these animals $[11,19]$. Pork has the highest infection rate of Toxoplasma cysts $[2,3]$ with beef having a relatively lower rate [20]. Cattle can be readily infected, but abortion or perinatal mortality has not been recorded; the available evidence suggests that cattle develop a more effective immune response to $T$. gondii infection than do other animals [16]. In meat-producing animals, tissue cysts of $T$. gondii are most frequently observed in tissues of infected pigs, sheep, and goats, and less frequently in infected poultry, rabbits, dogs, and horses. Tissue cysts are only rarely found in beef or buffalo meat $[8,19]$.

Vanderwangen et al. [20] reported a $29 \%$ serological examination based positive response of $T$. gondii in cattle in northern California. Sogandares-Bernal et al. [16] reported a rate of $38 \%$ in cattle sampled at Bitterroot, Montana. In a Korean study involving 84 native cattle, Moon and Kim [13] reported a serologically positive rate of $4.8 \%$ from Slaughtered cattle. Presently, the LAT revealed a positive rate of $3.8 \%$ in 105 cattle sampled from the Daejeon area. The result was similar to those of Moon and Kim [13]. Cattle can be liable to infection, but abortion or perinatal mortality has been recorded. The evidence suggests that cattle develop a more effective immune response to $T$. gondii infection than other animals [4]. Since 1953 the rate of miscarriage and death of newborn calves has not been prevalent. As a result, cattle farmers and clinical veterinarians have become less vigilant in the management of diseases such as toxoplasmosis [9, 17].

After two to three parturitions, female native Korean cattle are slaughtered to provide meat for human consumption. The ingestion of meat containing viable $T$. gondii tissue cysts is an important source of human infection $[5,9]$. It should be a concern that protozoan parasites cannot be treated with the anthelmintics sold in the open market, creating the possibility of Toxoplasma infection, although it is not necessarily the case that the intake of raw beef causes the infection. Cats are the definitive host of $T$. gondii. Stray cats are a common occurrence around cattle enclosures. Culling of these strays would be a prudent strategy to reduce infection. As well, the increased seropositive prevalence in older cattle warrants concern, although it should by no means be presumed that intake of raw beef is a guarantee of Toxoplasma infection.

The low prevalence of $T$. gondii in native Korean cattle in our study. However, the hazard analysis and critical control point (HACCP) protocol has been applied 
to cattle farms and beef traceability has been strengthen. These measures are welcome and will inspire consumer confidence and increased beef consumption. In this light, vigilance regarding Toxoplasma infection is important.

\section{References}

1. Buffolano W, Gilbert RE, Holland FJ, Fratta D, Palumbo F, Ades AE. Risk factors for recent Toxoplasma infection in pregnant women in Naples. Epidemiol Infect 1996, 116, 347-351.

2. Čatár G, Bergendi L, Holková R. Isolation of Toxoplasma gondii from swine and cattle. J Parasitol 1969, 55, 952-955.

3. Dienst RB, Verma MP. Isolation of Toxoplasma from salivary glands and saliva of pigs with asymptomatic infections. Am J Trop Med Hyg 1965, 14, 558-560.

4. Dubey JP. A review of Toxoplasmosis in cattle. Vet Parasitol 1986, 22, 177-202.

5. Dubey JP, Beattie CP. Toxoplasmosis of Animals and Man. pp. 100-120, CRC, Boca Raton, 1988.

6. Dubey JP, Miller NL, Frenkel JK. The Toxoplasma gondii oocyst from cat feces. J Exp Med 1970, 132, 636-662.

7. Esteban-Redondo I, Innes EA. Toxoplasma gondii infection in sheep and cattle. Comp Immunol Microbiol Infect Dis 1997, 20, 191-196.

8. Jacobs L, Remington JS, Melton ML. A survey of meat samples from swine, cattle, and sheep for the presence of encysted Toxoplasma. J Parasitol 1960, 46, 23-28.

9. Janitschke K. Animals as a source of Toxoplasma infection in man. Dtsch Med Wochenschr 1971, 96, 7883.

10. Kapperud G, Jenum PA, Stray-Pedersen B, Melby KK, Eskild A, Eng J. Risk factors for Toxoplasma gondii infection in pregnancy. Results of a prospective case-control study in Norway. Am J Epidemiol 1996, 144, 405-412.
11. Koestner A, Cole CR. Neuropathology of ovine and bovine toxoplasmosis. Am J Vet Res 1961, 22, 53-66.

12. Lee BH, Hwang BW, Byun YS, Lee SS, Kim CY, Suh MD. Survey on the distributions of swine Toxoplasma antibodies by latex agglutination test in Gyeongnam central area. Korean J Vet Serv 1992, 15, 174-183.

13. Moon MH, Kim DY. Latex agglutination test for toxoplasmosis and isolation of Toxoplasma from Slaughtered Cattle. Korean J Vet Public Health 1992, 16, 231-237.

14. Roh IS, Han JH, Kim JH, Ahn BW. Toxoplasmosis in piglets. Korean J Vet Res 1997, 37, 817-823.

15. Shin DW, Cha DY, Hua QJ, Cha GH, Lee YH. Seroprevalence of Toxoplasma gondii infection and characteristics of seropositive patients in general hospitals in Daejeon, Korea. Korean J Parasitol 2009, 47, 125-130.

16. Sogandares-Bernal F, Marchiondo AA, Duszynski DW, Ward JK. Prevalence of Toxoplasma antibodies in range vs. dairy cattle from the Bitterroot valley of Montana. J Parasitol 1975, 61, 965-966.

17. Sroka J, Zwolinski J, Dutkiewicz J, Tós-Luty S, Latuszyńska J. Toxoplasmosis in rabbits confirmed by strain isolation: a potential risk of infection among agricultural workers. Ann Agric Environ Med 2003, 10, 125-128

18. Suh MD, Joo HD, Maass D. Development of diagnostic kit (Test-MT) for the microplate latex agglutination test of toxoplasmosis in animal. Korean J Vet Res 1995, 35, 583-593.

19. Tenter AM, Heckeroth AR, Weiss LM. Toxoplasma gondii: from animals to humans. Int J Parasitol 2000, 30, 1217-1258.

20. Vanderwagen LC, Behymer DE, Riemann HP, Franti CE. A survey for Toxoplasma antibodies in northern California livestock and dogs. J Am Vet Med Assoc 1974, 164, 1034-1037. 